\title{
No environmental effect on vaccine-induced reduced growth in Atlantic salmon Salmo salar smolts
}

\author{
Thomas W. K. Fraser ${ }^{1, *}$, Per Gunnar Fjelldal ${ }^{1}$, Ingunn Sommerset ${ }^{2,5}$, Tina Søfteland ${ }^{2}$, \\ Ole Høstmark ${ }^{2}$, Mark D. Powell ${ }^{3,4}$, Vegar Heen ${ }^{3,4,6}$, Tom J. Hansen ${ }^{1}$ \\ ${ }^{1}$ Reproduction and Developmental Biology Group, Institute of Marine research (IMR), Matre 5, 5984 Matredal, Norway \\ ${ }^{2}$ MSD Animal Health Norge AS, Thormøhlensgate 55, 5008 Bergen, Norway \\ ${ }^{3}$ Disease and Pathogen Transmission, Institute of Marine Research, Nordnesgaten 50, 5005 Bergen, Norway \\ ${ }^{4}$ University of Bergen, Department of Biosciences, Thormøhlensgate 53A, 5020 Bergen, Norway \\ ${ }^{5}$ Present address: Norwegian Veterinary Institute, Thormøhlensgate 53C, 5006 Bergen, Norway \\ ${ }^{6}$ Present address: Pharmaq AS, Harbitzalléen 2A, 0275 Oslo, Norway
}

\begin{abstract}
Oil-adjuvanted vaccines reduce long-term growth in farmed Atlantic salmon Salmo salar, possibly via an increase in metabolic rate due to the energetic demands of the immune system. We tested this hypothesis by comparing sham-vaccinated to vaccinated smolts (total $\mathrm{n}=$ 2096, ca. $80 \mathrm{~g})$ under different scenarios of water temperature $\left(12 \mathrm{vs} .17^{\circ} \mathrm{C}, \mathrm{n}=1048\right.$ per temperature) and oxygen $\left(\mathrm{O}_{2}\right)$ saturation $\left(60,70,80\right.$, and $100 \%, \mathrm{n}=524$ per $\mathrm{O}_{2}$ saturation level) in order to manipulate metabolic rate and $\mathrm{O}_{2}$ availability. We expected a more severe vaccination effect under conditions of high water temperature and low $\mathrm{O}_{2}$ saturation. Groups were kept in duplicate tanks under controlled temperature and hypoxia conditions for $7 \mathrm{wk}$ post-vaccination before being transferred to uncontrolled common-garden natural conditions for $5 \mathrm{mo}$ in a sea-cage. Body mass and length were recorded at the initiation and end of the controlled and uncontrolled environmental conditions. Vaccination and low $\mathrm{O}_{2}$ saturation at $17^{\circ} \mathrm{C}$ significantly reduced body mass (13 and 3\% through vaccination and 9 and $20 \%$ through $60 \% \mathrm{O}_{2}$ saturation at the end of the tank and sea-cage periods, respectively). However, there was no interaction between vaccination, temperature, and $\mathrm{O}_{2}$ saturation at the end of the tank or sea-cage period, lending no support to our hypothesis. A secondary observation was that emaciated 'loser' fish were mainly associated with the $17^{\circ} \mathrm{C}$ and low (mainly $60 \%$ ) $\mathrm{O}_{2}$ saturation treatment. In conclusion, although vaccination led to a reduction in body mass, this effect was not influenced by environmental conditions expected to alter metabolic rate.
\end{abstract}

KEY WORDS: Dissolved oxygen · Hypoxia · Immunity · Antibody · Temperature · Cataracts · Losers $\cdot$ Skeletal deformity

\section{INTRODUCTION}

Salmon farming in Norway relies on the protection provided by multi-component vaccines, and this has contributed both to the growth of the industry and its relatively low level of antibiotic use compared to other salmon farming regions (Love et al. 2020).

\footnotetext{
${ }^{*}$ Corresponding author: thomas.fraser@hi.no
}

However, oil-adjuvanted vaccines induce abdominal lesions and peritonitis (Midtlyng et al. 1996), lead to short-term reductions in feed intake (Sørum \& Damsgård 2004), and reduce growth by between 9 and $23 \%$ post-vaccination (Midtlyng \& Lilllehaug 1998, Fraser et al. 2014). Furthermore, tissue-specific inflammation and systemic autoimmunity has been suggested

() The authors 2020. Open Access under Creative Commons by Attribution Licence. Use, distribution and reproduction are unrestricted. Authors and original publication must be credited. 
to be induced by multivalent oil-adjuvanted vaccines (Koppang et al. 2008, Haugarvoll et al. 2010), and an increased risk of skeletal deformities has been reported (Berg et al. 2006). The adjuvants are necessary in order to provide long-term protection due to slow release of the antigens within the peritoneal cavity, but the adjuvants are also related to the occurrence of many of the unwanted side effects (Midtlyng et al. 1996). Although improvements have been made in reducing the severity and frequency of vaccine side effects, they still occur (Brudeseth et al. 2013).

The immune system is energetically demanding, due to the metabolic requirement of immune cells, but also through indirect consequences such as tissue degradation or anorexia during inflammation (Lochmiller \& Deerenberg 2000). As oil-adjuvanted salmon vaccines lead to a chronically active immune response that peaks at 6 mo post-vaccination (Mutoloki et al. 2004, 2006), one may suspect that the reduced growth is a result of an increased metabolic cost of the immune system. Indeed, several studies have found increases in standard metabolic rate following vaccination in fish. For example, rainbow trout Oncorhynchus mykiss vaccinated against Aeromonas salmonicida (Ackerman et al. 2000) or with a DNA vaccine (Skinner et al. 2010) have an increase in oxygen $\left(\mathrm{O}_{2}\right)$ consumption. In addition, Fraser et al. (2015) observed an increase in heart size in vaccinated vs. unvaccinated fish, which is suggestive of an increase in cardiac workload that one may expect with an increase in metabolic demand. Finally, an increase in abdominal lesions in salmon vaccinated at what is considered high $\left(16^{\circ} \mathrm{C}\right)$ versus lower $\left(10^{\circ} \mathrm{C}\right)$ water temperature has also been observed (Grini et al. 2011). Here, as factorial aerobic scope is known to be reduced with increasing environmental temperature in salmon (Hvas et al. 2017), one may speculate that higher than optimal temperatures may reduce the amount of energy available to the immune system that is expected to be energy-demanding (Lochmiller \& Deerenberg 2000).

Our main objective was to investigate whether vaccine-induced reduced growth could be related to metabolic demands. Our hypothesis was that reduced growth is due to an increase in metabolic demand following vaccination. To this end, we manipulated water temperature (to alter metabolic rate) and $\mathrm{O}_{2}$ saturation to produce various levels of metabolic limitation in vaccinated and unvaccinated salmon. The various environmental conditions, all combinations of 12 vs. $17^{\circ} \mathrm{C}$, and $60,70,80$, and $100 \% \mathrm{O}_{2}$ saturation, were maintained for 1 mo following vaccination. Water temperature is positively associated with metabolic rate in salmon (Hvas et al. 2017), and the ability to withstand hypoxia decreases exponentially between 6 and $18^{\circ} \mathrm{C}$ (Remen et al. 2013). As such, based on cyclic hypoxia studies, we expect $\leq 60 \% \mathrm{O}_{2}$ saturation to be physiologically challenging at $17^{\circ} \mathrm{C}$, but not at $12^{\circ} \mathrm{C}$ (Remen et al. 2012, 2013). As a secondary objective, we also report on the long-term effects of the environmental conditions and vaccination on growth and production characteristics (antibody production, 'loser' fish (hereafter referred to as 'losers'), post-smolt maturation, cataracts, radiological deformities) during 5 mo of common garden rearing in a sea-cage.

\section{MATERIALS AND METHODS}

\subsection{Fish stock and rearing conditions}

Atlantic salmon Salmo salar from the Aquagen strain were reared from first feeding (14 March 2016) at the Institute of Marine Research (IMR) facilities at Matre Research Station. Throughout, fish were fed standard diets (Skretting) with an estimated 20\% surplus based on estimated growth. The temperature and photoperiod throughout the experiment are summarized in Fig. 1. In brief, the temperatures and photoperiods used prior to the study are commonly used to rear underyearling (i.e. 0+) smolts. As such, a square wave photoperiod was used to initiate smoltification. Prior to vaccination, the fish were moved to $1 \times 1 \mathrm{~m}$ tanks $(\mathrm{n}=10)$ on 28 August 2016 ( $\mathrm{n}=2096$ fish, mean weight $50 \mathrm{~g}, 10.5 \mathrm{~kg} \mathrm{~m}^{-3}$ ). Between 9 and 12 September 2016, the fish were implanted with a passive integrated transponder (PIT) tag that allows for individual recognition and distributed among 16 tanks $(1 \times 1 \mathrm{~m} ; \mathrm{n}=131$ fish $\operatorname{tank}^{-1}$ ). Between 3 and 10 October 2016, the experimental conditions were set according to Table 1. On 10 October 2016, approximately half of the fish (65-66 tank ${ }^{-1}$ ) were vaccinated with $0.1 \mathrm{ml}$ AQUAVAC ${ }^{\circledR}$ PD7 vet. (MSD Animal Health, vaccine against salmon pancreas disease virus, infectious pancreatic necrosis virus, Aeromonas salmonicida subsp. salmonicida, Vibrio anguillarum serotype $\mathrm{O} 1$ and O2a, V. salmonicida, and Moritella viscosa; further details can be found online at www.felleskatalogen.no), whilst the remaining fish received $0.1 \mathrm{ml}$ of sterile saline via an intra-peritoneal injection (i.e. unvaccinated controls) according to standard operating procedures (initial body size of each group can be found in Fig. S1 in Supplement 1 at www.int-res. com/articles/suppl/q012p327_supp/, for all supplemental figures). The vaccinated and unvaccinated 


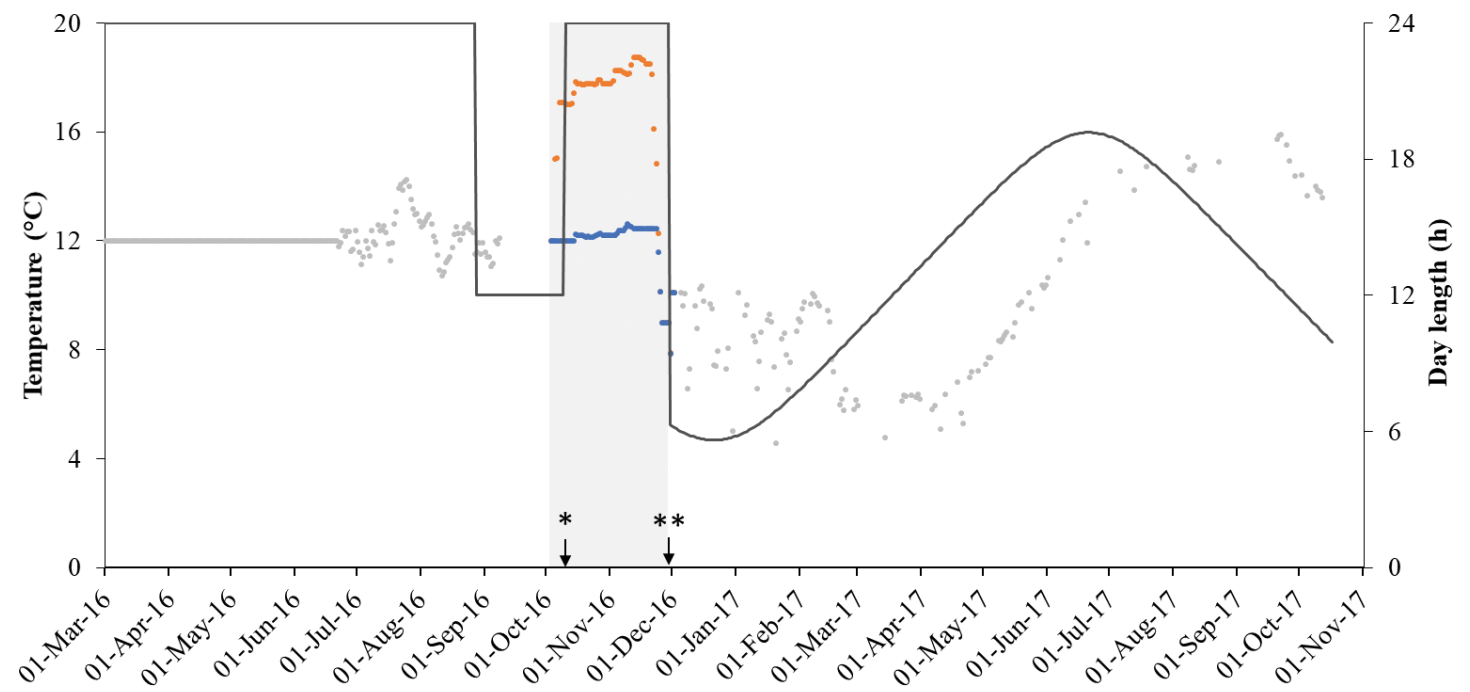

Fig. 1. Temperature (dots) and photoperiod (solid line) during the experiment. The grey zone represents the period of $\mathrm{O}_{2}$ saturation (see Table 1) and temperature manipulation. Here, half of the fish were held at $\sim 17^{\circ} \mathrm{C}$ (orange) and the other half at $\sim 12^{\circ} \mathrm{C}$ (blue); otherwise, the fish were reared under a common temperature (grey dots). *Time of vaccination and $* *$ fish transferred to common-garden rearing within a sea-cage

Table 1. Daily overview during the initiation of the environmental conditions for Atlantic salmon reared under different controlled conditions of temperature and oxygen $\left(\mathrm{O}_{2}\right)$ saturation

\begin{tabular}{|c|c|c|c|c|c|c|c|c|c|c|}
\hline \multirow[t]{2}{*}{ Date } & \multicolumn{5}{|c|}{$\begin{array}{l}12^{\circ} \mathrm{C} \text { groups } \\
\text { Temp. Oxygen saturation (\%) }\end{array}$} & \multicolumn{5}{|c|}{$\begin{array}{l}-17^{\circ} \mathrm{C} \text { groups } \\
\text { Temp. Oxygen saturation }(\%)\end{array}$} \\
\hline & $\left({ }^{\circ} \mathrm{C}\right)$ & 60 & 70 & 80 & 100 & $\left({ }^{\circ} \mathrm{C}\right)$ & 60 & 70 & 80 & 100 \\
\hline 03.10 .2016 & 12 & 100 & 100 & 100 & 100 & 12 & 100 & 100 & 100 & 100 \\
\hline 04.10 .2016 & 12 & 80 & 80 & 80 & 100 & 12 & 80 & 80 & 80 & 100 \\
\hline 05.10 .2016 & 12 & 70 & 70 & 80 & 100 & 15 & 70 & 70 & 80 & 100 \\
\hline 06.10 .2016 & 12 & 60 & 70 & 80 & 100 & 15 & 60 & 70 & 80 & 100 \\
\hline 07.10 .2016 & 12 & 60 & 70 & 80 & 100 & 17 & 60 & 70 & 80 & 100 \\
\hline
\end{tabular}

fish were mixed in the same tanks (i.e. common garden). The water flow into the tanks was switched to seawater on 2 November 2016 for those fish reared at $17^{\circ} \mathrm{C}$, and on 10 November 2016 for those fish reared at $12^{\circ} \mathrm{C}$. The difference in seawater timing was related to the number of degree-days (the sum of the daily temperature) required for smoltification to peak. Here, 350 degree-days after the end of the winter signal are required to complete smoltification (i.e. Handeland et al. 2004). On 30 November 2016, all fish were transferred to a single sea-cage $(5 \times 5 \times$ $7 \mathrm{~m}$, stocking density of $1.2 \mathrm{~kg} \mathrm{~m}^{-3}$ ) for commongarden rearing under natural temperatures and light $\left(60^{\circ} \mathrm{N}\right)$. Data from the control fish reared at $100 \% \mathrm{O}_{2}$ saturation were previously reported in another study detailing the occurrence of out-of-season post-smolt sexual maturation (Fraser et al. 2019a).

On 18 November, an unexplained mortality event occurred in 1 tank with $100 \% \mathrm{O}_{2}$ from the $12^{\circ} \mathrm{C}$ group, wherein 14 fish died. Of these, $50 \%$ were unvaccinated, so mortality was not related to vaccination. A comparison of growth rates between this tank and the second tank belonging to this group showed no short- or longterm differences in mean body mass; therefore, these fish were included in all of the analyses (data not shown, but the models are given in Supplement 2 at www.int-res.com/articles/ suppl/q012p327_supp/).

\subsection{Sampling protocol}

Body mass, fork length, and PIT tag number were collected from all fish at 3 time points: 10 October 2016 (vaccination), 30 November 2016 (transfer to sea-cage), and 26 April 2017 (end of seawinter, 28 wk post-vaccination). At each sampling time, fish were anaesthetised in $100 \mathrm{mg} \mathrm{l}^{-1}$ Finquel $^{\circledR}$ (MS 222) prior to handling. Gills (stored in RNA later for gene expression) and blood serum (for antibody assessment, frozen at $-80^{\circ} \mathrm{C}$ ) were collected from 8-11 vaccinated and 9-12 unvaccinated, terminally anaesthetised fish from each of the $100,80,70$, and $60 \% \mathrm{O}_{2}$ groups (46 fish group $^{-1} \operatorname{tank}^{-1}$ ) at 2, 4, and 6 wk post-vaccination, and blood serum was also collected in Week 28 (on 26 April 2017). These time points were chosen to provide good resolution in the development of smoltification and the antibody response. Here, all groups tested 
(the $70 \% \mathrm{O}_{2}$ groups were not included) were considered seawater-adapted at $4\left(17^{\circ} \mathrm{C}\right.$ groups $)$ and $6\left(12^{\circ} \mathrm{C}\right.$ groups) wk post-vaccination following gill gene expression analyses $\left(\mathrm{Na}^{+} \mathrm{K}^{+}\right.$-ATPase isoforms $\alpha 1 \mathrm{a}$ and $\alpha 1 \mathrm{~b}$, i.e. Houde et al. 2019) by Pharmaq Analytic (Fig. S2). Cataracts (yes/no) were identified in April 2017 by visual observation of both eyes, and losers (yes/no) were identified subjectively in April 2017 based on external appearance (i.e. losers being notably small and thin, i.e. emaciated). In April 2017, a sub-sample of fish $(\mathrm{n}=80)$ from the vaccinated and unvaccinated 60 and $100 \% \mathrm{O}_{2}$ saturation groups $\left(\mathrm{n}=10\right.$ group $\left.^{-1}\right)$ were terminally anaesthetised and frozen for later radiological assessment of the vertebral column. Levels of sexual maturation, based on external morphology (see Fjelldal et al. 2018), were assessed throughout. Mature male post-smolts were identified by running milt, whereas females showed no sign of maturity based on the relative size of the gonopore. At the end of the study, all remaining fish were terminally anaesthetised and sexed by visual examination of the gonads.

The condition factor $(\mathrm{CF})$ was calculated as $\mathrm{CF}=$ weight $(\mathrm{g}) /$ length $^{3}(\mathrm{~cm}) \times 100$. Specific growth rate $\left(\mathrm{SGR}, \% \mathrm{~d}^{-1}\right)$ was calculated from the formula: $\mathrm{SGR}=$ $\left(e^{q}-1\right) \times 100$ (Houde \& Scheckter 1981), where $q=$ $\left[\operatorname{In}\left(W_{2}\right)-\operatorname{In}\left(W_{1}\right)\right]\left(t_{2}-t_{1}\right)^{-1}$ (Bagenal \& Tesch 1978) and where $W_{2}$ and $W_{1}$ were the live body weights in grams at times $t_{2}$ and $t_{1}$, respectively. The thermal growth coefficient (TGC) was also calculated as $\mathrm{TGC}=\left(W_{2}{ }^{1 / 3}-W_{1}{ }^{1 / 3}\right) /\left(\right.$ temperature $\left[{ }^{\circ} \mathrm{C}\right] \times$ number of days) $\times 1000$ (Cho 1992) .

\subsection{Radiology}

Frozen fish were thawed and filleted to remove surrounding flesh around the vertebral column to increase the quality of the radiograph images. The vertebral columns were radiographed (Porta $100 \mathrm{HF}$; Eickemeyer Medizintechnik für Tierärzte) using a $35 \times 43 \mathrm{~cm}$ image plate in a rigid cassette (Dürr Medical) with $40 \mathrm{kV}$ and $10 \mathrm{mAs}$ at a distance of $70 \mathrm{~cm}$. The image plate was scanned (CR $35 \mathrm{VET}$; Dürr Medical) and the resulting image converted into a TIFF file (Vet-Exam Plus Software, version 4.14.0). Evaluation of vertebral deformities was done according to the classification of Witten et al. (2009).

\subsection{Antibody assay}

Enzyme-linked immunosorbent assay (ELISA) was used to determine the antibody titre in Atlantic salmon sera against one of the vaccine antigens, Aeromonas salmonicida subsp. salmonicida. Microtitre plates (96-well Nunc MaxiSorp, ThermoFischer Scientific) were coated overnight with $A$. salmonicida antigen $\left(4.8 \times 10^{6}\right.$ cells well $\left.{ }^{-1}\right)$ and blocked for $1 \mathrm{~h}$ at $20^{\circ} \mathrm{C}$ with phosphate buffered saline (PBS) (Sigma Aldrich) with $1 \%$ bovine serum albumin (BSA). Serum was diluted with PBS with 1\% BSA in initial dilutions of $1: 100,1: 400,1: 800$, or $1: 1600$, at Weeks $2,4,6$, and 28 , respectively. The samples were serially diluted by 2-fold dilution and incubated overnight between -2 and $-8^{\circ} \mathrm{C}$. Each plate included a positive and negative control serum (obtained from vaccinated and unvaccinated salmon). After incubation, microtitre plates were washed 3 times $\left(250 \mu \mathrm{l}\right.$ well $\left.^{-1}\right)$ with PBS and Tween (polysorbate) 20 (PBS-Tw) (Merck Millipore) in an ELISA microplate washer (ELx405, BioTek). Rabbit-anti-salmon antibodies were used as secondary antibody $\left(2^{\circ} \mathrm{Ab}\right)$ and, along with the conjugate (mouse-anti-rabbit HRP), were provided by Intervet International Boxmeer. The $2^{\circ} \mathrm{Ab}$ and the conjugate were diluted at 1:12000 and 1:16000, respectively. After incubation with the $2^{\circ} \mathrm{Ab}$, the plates were washed 3 times using PBS-Tw. Plates were washed 6 times with PBS-Tw after incubation with the conjugate. The colour substrate 3,3',5,5'-tetramethylbenzidine was diluted 1:60 with distilled water and ureum-peroxide buffer (Intervet International) before transferring $100 \mu \mathrm{l}$ into each well. The reaction was stopped after $20 \mathrm{~min}$ by adding $50 \mu \mathrm{l}$ of sulphuric acid (4 $\mathrm{NH}_{2} \mathrm{SO}_{4}$ ) into each well. Absorbance was read using a microplate reader (Sunrise, Tecan Group) at $450 \mathrm{~nm}$. The raw data were imported into the analysis software CBA AbendVertical V1.21 (MSD, Proprietary Software) to calculate the antibody titres. The mean negative control value $\times 5$ was used to set the threshold for calculating the antibody titres of the sampled sera, which were expressed in $\log ^{2}$, as the maximum dilution corresponding to this threshold.

\subsection{Statistical analyses}

The data were transferred to $\mathrm{R}$ version 3.6.0 ( $\mathrm{R}$ Development Core Team, www.r-project.org). Significance was assigned at $\mathrm{p}<0.05$. All raw data can be found in Supplement 3 at www.int-res.com/articles/ suppl/q012p327_supp/ (see tabs 'Growth', 'Prevalences', and 'Immunity') and the R script (Supplement 2) used to analyse the data. The data from 126 fish were removed from the analysis due to duplicate or triplicate PIT tag numbers (ranging from 1-27 vaccine $^{-1}$ temperature ${ }^{-1} \mathrm{O}_{2}$ saturation ${ }^{-1}$ ). 
We compared models that either supported or rejected our hypothesis using the Bayesian information criterion (BIC). Two models were generated: (1) water temperature $\left(12 / 17^{\circ} \mathrm{C}\right) \times \mathrm{O}_{2}$ saturation $(60 / 70 / 80 /$ $100 \%$, categorical) $\times$ vaccination $($ yes $/$ no $)+$ sex (male/ female); and (2) water temperature $\times \mathrm{O}_{2}$ saturation + vaccination + sex (male/female). The first model provides evidence that vaccine side-effects are dependent on metabolic demand, whereas the second model lends support to vaccine side-effects being independent of metabolic demands. Each time point was analysed separately, as we know time effects exist for the effects of water temperature on long-term growth (Grini et al. 2011), but there are no data on how $\mathrm{O}_{2}$ saturation and water temperature interact, and a 4way interaction (i.e. water temperature $\times \mathrm{O}_{2}$ saturation $\times$ vaccination $\times$ time) was rejected due to complexity. We also controlled for sex due to its influence on body size even in immature fish (Fraser et al. 2014). The model with the lowest BIC score was considered the 'true' model (Aho et al. 2014). Type II sums of squares were used for models without interactions, whereas main effects were calculated using type III sums of squares when interactions were present within the final model. Post hoc tests were done using least square means with a Tukey adjustment from the 'emmeans' library, whereby means for groups are adjusted for means of other factors within the model (Lenth 2016). The same model was used for SGR, but the body weight at the start of the investigated period was included as a main effect to control for differences in initial body size, as smaller fish tend to have higher growth rates (i.e. water temperature $x$ $\mathrm{O}_{2}$ saturation $\times$ vaccination + start mass + sex). Models for TGC are included in Supplement 2, but mirror the results of SGR and so are not presented.

To assess the prevalence of cataracts, we used the exact binomial test using the 'binom.test' command. To compare $\mathrm{O}_{2}$ saturation, multiple comparisons were made (60 vs. $100 \%, 70$ vs. $100 \%, 80$ vs. $100 \%$ ); therefore, a Bonferroni correction was made with significance assigned at $\mathrm{p}<0.017$.

To determine whether antibody response could be affected by environmental conditions, we used generalised least square models. Both temperature (Eggset et al. 1997), $\mathrm{O}_{2}$ saturation (Kvamme et al. 2013), and their interaction (Niklasson et al. 2011) influence the immune response in fish, whereas antibody production initially increases before reaching a plateau over time (Eggset et al. 1997). Therefore, we compared an initial model of water temperature $\times \mathrm{O}_{2}$ saturation $\times$ time (week 2/4/6/28 post vaccination, categorical) with a second model of water tempera- ture $\times$ time $+\mathrm{O}_{2}$ saturation $\times$ time. The models were corrected with the 'weights=varPower()' command to correct for heteroskedasticity within the model residuals. For these models, only data from vaccinated fish were included, as unvaccinated fish from all groups showed low levels of antibody titres throughout ( $<6.6$ titre; data not shown, but can be found in Supplement 3).

Due to an interest in the occurrence of losers, we included models to assess their relative performance compared to 'normal' fish, i.e. immature fish without cataracts. Here, as expected (e.g. Fjelldal et al. 2011, Imsland et al. 2014, Fraser et al. 2019a), exploratory statistics demonstrated that males that matured as post-smolts were heavier in November 2016, but smaller in April 2017, compared to immature males (Fig. S3A). Also, as expected (e.g. Bjerkås et al. 2001), fish with cataracts became smaller from November 2016 onwards compared to fish without cataracts (Fig. S3B). Therefore, these fish were not included when assessing the performance of losers. For losers, we used data from the $17^{\circ} \mathrm{C}$ and $60 \% \mathrm{O}_{2}$ saturation groups only, as this is where $87 \%$ (13 of 15) of the losers were observed. Two initial linear mixed effect (LME) models were produced to explore body mass and body condition: (1) loser (yes/no) $\times$ time (October 2016/November 2016/April 2017, categorical) + sex (male/female) + vaccination (yes/no); and (2) loser + time + sex + vaccination. The first model provided evidence that losers show transient growth effects over time, whereas the second model demonstrated that any loser effect was independent of time. In these last 2 models, fish ID was included as a random effect to account for repeated sampling of the same individuals. In addition, only fish for which data were available at all time points were included.

All model residuals were checked for normality following visual examination of $\mathrm{q}-\mathrm{q}$ plots, and the model accuracy was checked using standardised residuals vs. fitted residual plots. If the model residuals failed to meet normality, the data were transformed using either natural log transformation (body mass in October 2016 and November 2016, body mass for losers, maturity, and cataract models), the 'weights=varPower()' to correct for heteroskedasticity (blood titres), or Tukey's ladder of powers (body mass in April 2017, SGR in April 2017) using the 'transformTukey' command from the 'rcompanion' library that finds the power transformation that makes the data fit the normal distribution as closely as possible. All models that included transformations gave results similar to models without transformations (see Supplement 2 for details). For models that assessed 
growth over time, only those fish with data available from every time point were analysed.

\section{RESULTS}

\subsection{Mortality}

Total mortality was $<6 \%$ in all groups at termination of the experiment (Fig. S4). Mortality prior to transfer to the sea-cage was low $(<1 \%$ in any one group) and could not be analysed statistically. There was no general effect of vaccination or $\mathrm{O}_{2}$ saturation, but the fish reared at $12^{\circ} \mathrm{C}$ had significantly lower mortality than those reared at $17^{\circ} \mathrm{C}$.

\subsection{Effects of vaccination on growth during controlled environmental conditions}

Vaccinated fish were significantly smaller than their unvaccinated counterparts (Fig. 2A) due to reduced growth rates (Fig. 2B), irrespective of environmental treatment. Those fish kept on $60 \% \mathrm{O}_{2}$ saturation were significantly smaller than all other groups at $17^{\circ} \mathrm{C}$, but not at $12^{\circ} \mathrm{C}$ (Fig. 2A). However, there was a generally positive association between growth rates and hypoxia that was more apparent at $17^{\circ} \mathrm{C}$ compared to $12^{\circ} \mathrm{C}$ (Fig. 2B). There was no interaction between vaccination and environmental conditions, as the models that included the interaction had consistently higher BIC scores than those without (November 2016 body mass, -742 vs. -780 and SGR, 371 vs. 339 for the interaction and no interaction, respectively).

\subsection{Effects of vaccination and historic environmental conditions on growth under natural uncontrolled conditions}

Vaccinated fish were still significantly smaller following 5 mo of common garden conditions than unvaccinated fish (Fig. 2C), but they had significantly higher growth rates during this period (Fig. 2D). Fish previously exposed to hypoxia at $17^{\circ} \mathrm{C}$ had significantly lower growth rates than fish previously kept on $100 \% \mathrm{O}_{2}$ saturation (Fig. 2D), resulting in these fish being significantly smaller at the end of the trial (Fig. 2C). Fish previously reared at $12^{\circ} \mathrm{C}$ showed no hypoxia effect on long-term growth. However, there was no interaction between vaccination and historic environmental conditions, as the models that included the interaction had consistently higher BIC scores than those without (April 2017 body mass, 22015 vs. 21981 and SGR, 9639 vs. 9596 for the interaction and no interaction, respectively). The effects of vaccination and environmental conditions on growth were not explained by group differences in the levels of sexual maturation and/or cataracts (data not shown, but the models are provided in Supplement 2).

\subsection{Production parameters}

Sexually mature fish, losers, and those with cataracts were only found in groups that experienced $17^{\circ} \mathrm{C}$ (Fig. 3). There was no effect of vaccination on the prevalence of mature fish, but there was a non-significant trend for decreasing levels of sexual maturation with lower $\mathrm{O}_{2}$ saturation in the $17^{\circ} \mathrm{C}$ fish (Fig. 3A). Cataract prevalence was significantly higher in unvaccinated compared to vaccinated fish (Fig. 3B). Losers were almost exclusively found among fish reared on $60 \% \mathrm{O}_{2}$ saturation, irrespective of the vaccination status (Fig. 3C). There was no effect of vaccination or $\mathrm{O}_{2}$ saturation on skeletal deformities, as only 2 out of the 80 radiographed fish had any deformed vertebrae. Both of these fish were previously reared on $60 \% \mathrm{O}_{2}$ saturation at $17^{\circ} \mathrm{C}, 1$ vaccinated (2 deformed vertebrae) and 1 unvaccinated (15 deformed vertebrae).

\subsection{Antibody production}

There was no interaction between temperature and $\mathrm{O}_{2}$ saturation on antibody titres over time. However, those fish vaccinated at $17^{\circ} \mathrm{C}$ had significantly higher antibody titres at Weeks 2, 4, and 6 post-vaccination when under control environmental conditions, but not in April 2017 after 5 mo in natural uncontrolled conditions (28 wk post-vaccination), compared to those vaccinated at $12^{\circ} \mathrm{C}$ (Fig. $4 \mathrm{~A}$ ). In addition, the interaction between $\mathrm{O}_{2}$ saturation and time was close to significant, as the fish vaccinated at $60 \% \mathrm{O}_{2}$ saturation had significantly lower antibody titres than those vaccinated at $100 \% \mathrm{O}_{2}$ saturation in April 2017 , but not at Weeks 2, 4, and 6 post-vaccination (Fig. 4B).

\subsection{Losers}

Based on the subjective assessment, losers were found to be exclusively the smallest fish in April 2017 (no overlap with 'normal' fish, with the minimum value for 'normal' fish being $150 \mathrm{~g}$ and the maximum value for losers being $128 \mathrm{~g}$ ), with a CF of $<0.94$ that 
O Unvaccinated $\nabla$ Vaccinated $\square 12^{\circ} \mathrm{C} \quad \square 17^{\circ} \mathrm{C}$

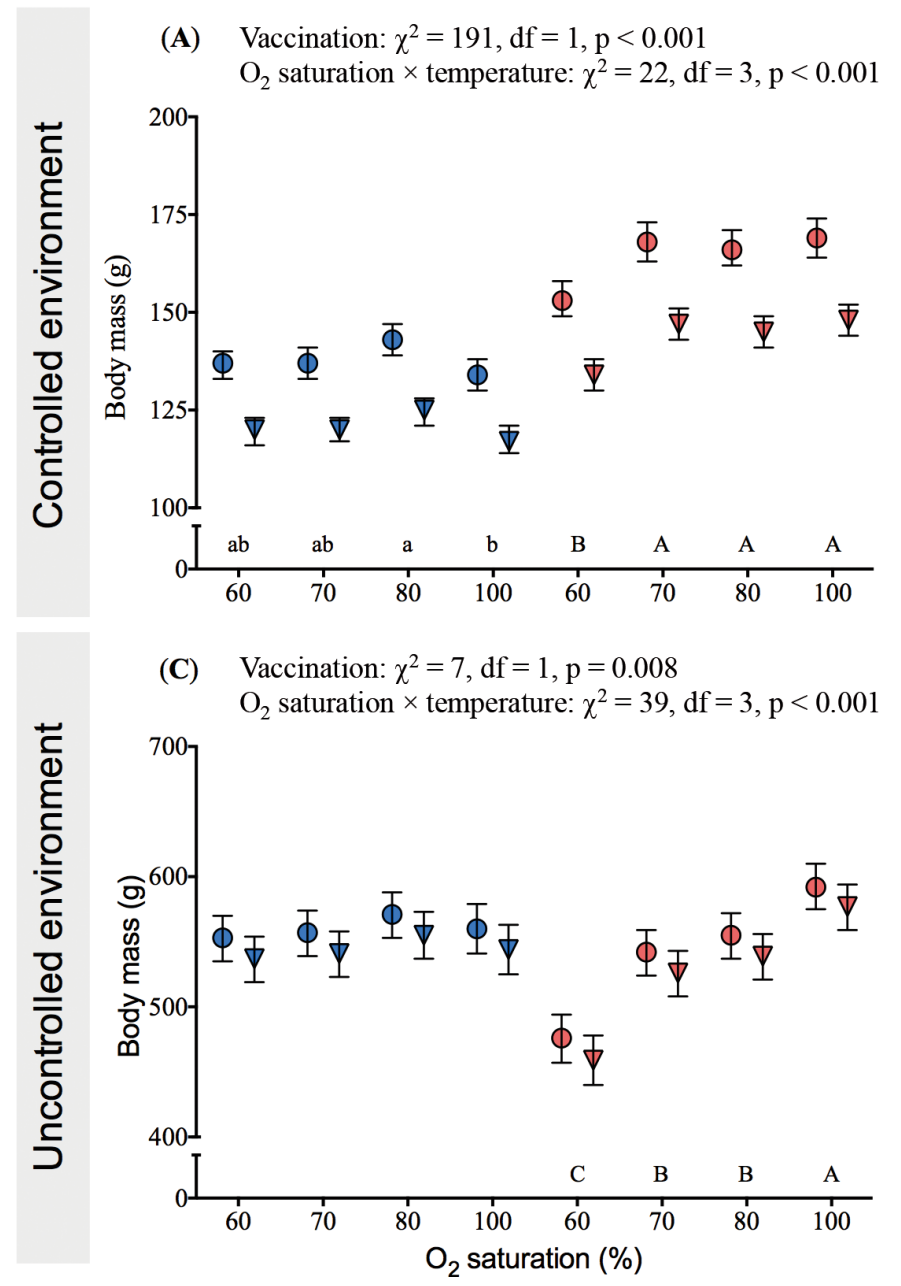

(B) Vaccination: $\chi^{2}=379$, df $=1, \mathrm{p}<0.001$

$\mathrm{O}_{2}$ saturation $\times$ temperature: $\chi^{2}=17, \mathrm{df}=3, \mathrm{p}<0.001$

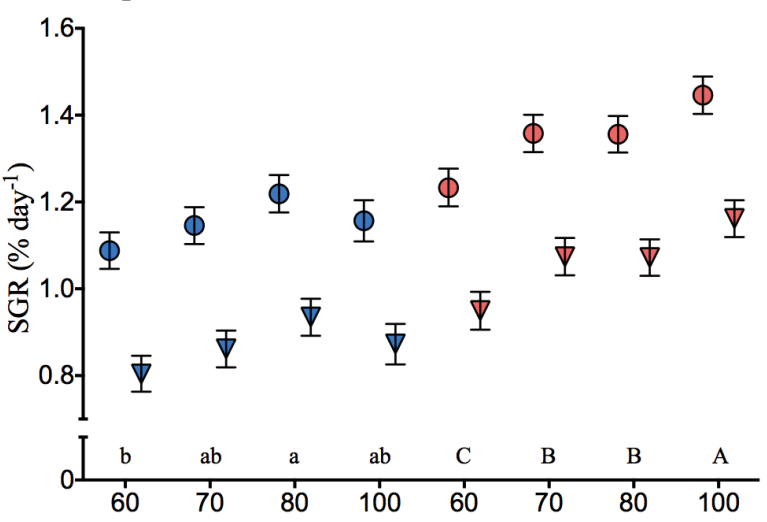

(D) Vaccination: $\chi^{2}=28, \mathrm{df}=1, \mathrm{p}<0.001$

$\mathrm{O}_{2}$ saturation $\times$ temperature: $\chi^{2}=26, \mathrm{df}=3, \mathrm{p}<0.001$

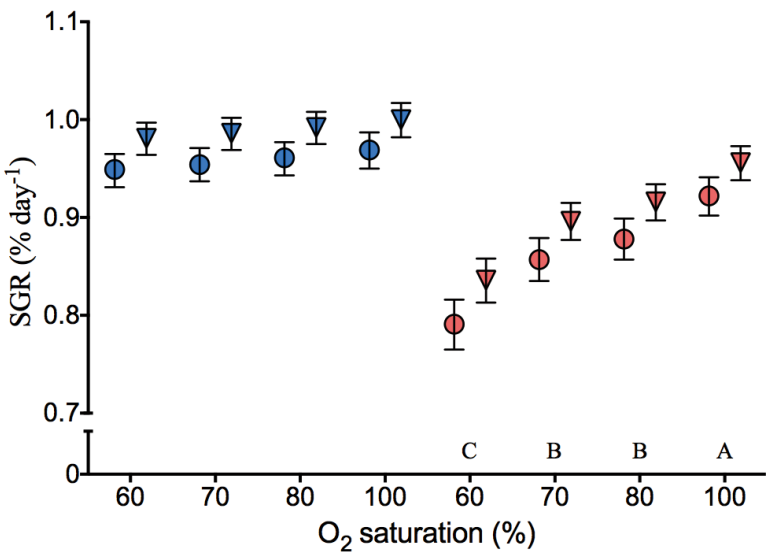

Fig. 2. Body mass and growth data over time for vaccinated and unvaccinated Atlantic salmon reared under different controlled conditions of temperature and oxygen $\left(\mathrm{O}_{2}\right)$ saturation between 10 October and 30 November 2016 before commongarden rearing in uncontrolled environmental conditions within a sea-cage. (A) Body mass on 30 November 2016, (B) specific growth rate (SGR) between 10 October and 30 November 2016, (C) body mass on 26 April 2017, and (D) SGR between 30 November 2016 and 26 April 2017. Data are means $\pm 95 \%$ CI $\left(n=67-89\right.$ group $^{-1}$ time $\left.^{-1}\right)$. The results from linear mixed effect models are presented for each time point. Different lowercase letters indicate significant $\mathrm{O}_{2}$ saturation effects at $12^{\circ} \mathrm{C}$ whereas uppercase letters indicate significant $\mathrm{O}_{2}$ saturation effects at $17^{\circ} \mathrm{C}$ (post hoc, least square means, $\mathrm{p}<0.05$ )

(A)

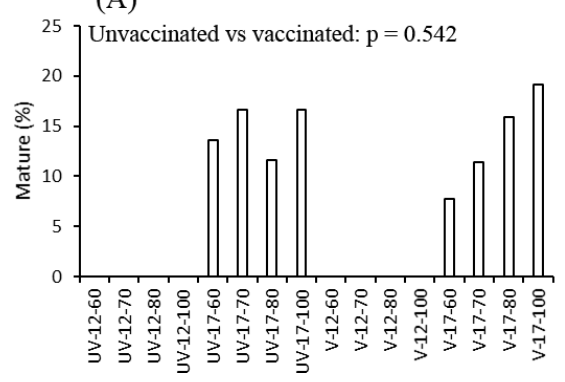

(B)

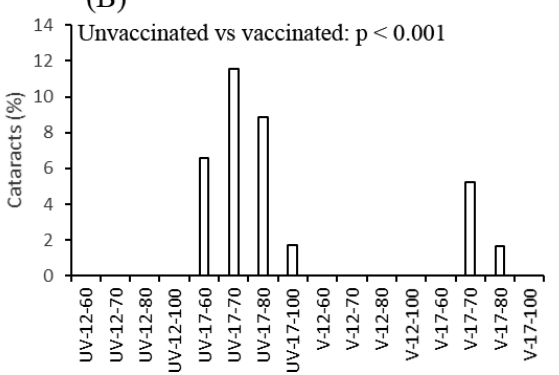

(C)

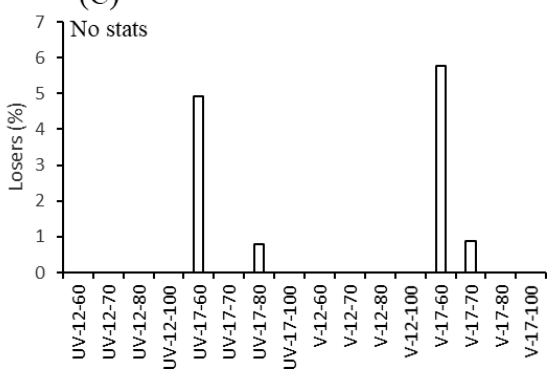

Fig. 3. Percentage of Atlantic salmon that (A) sexually matured as post-smolts, (B) had cataracts, and (C) were 'losers'. The statistics are from binomial tests of specific parameters. Data are $(A) \%$ of males only $\left(n=34-47\right.$ group $\left.^{-1}\right)$ and $(B, C) \%$ of the whole population $\left(\mathrm{n}=96-122\right.$ group $\left.^{-1}\right)$. Groups on the $x$-axis are categorised by vaccination status (UV: unvaccinated, V: vaccinated)temperature $\left(12\right.$ or $\left.17^{\circ} \mathrm{C}\right)-\mathrm{O}_{2}$ saturation $(60,70,80,100 \%)$ 
(A) Temperature $\times$ time: $\chi^{2}=58$, df $=3, p<0.001$
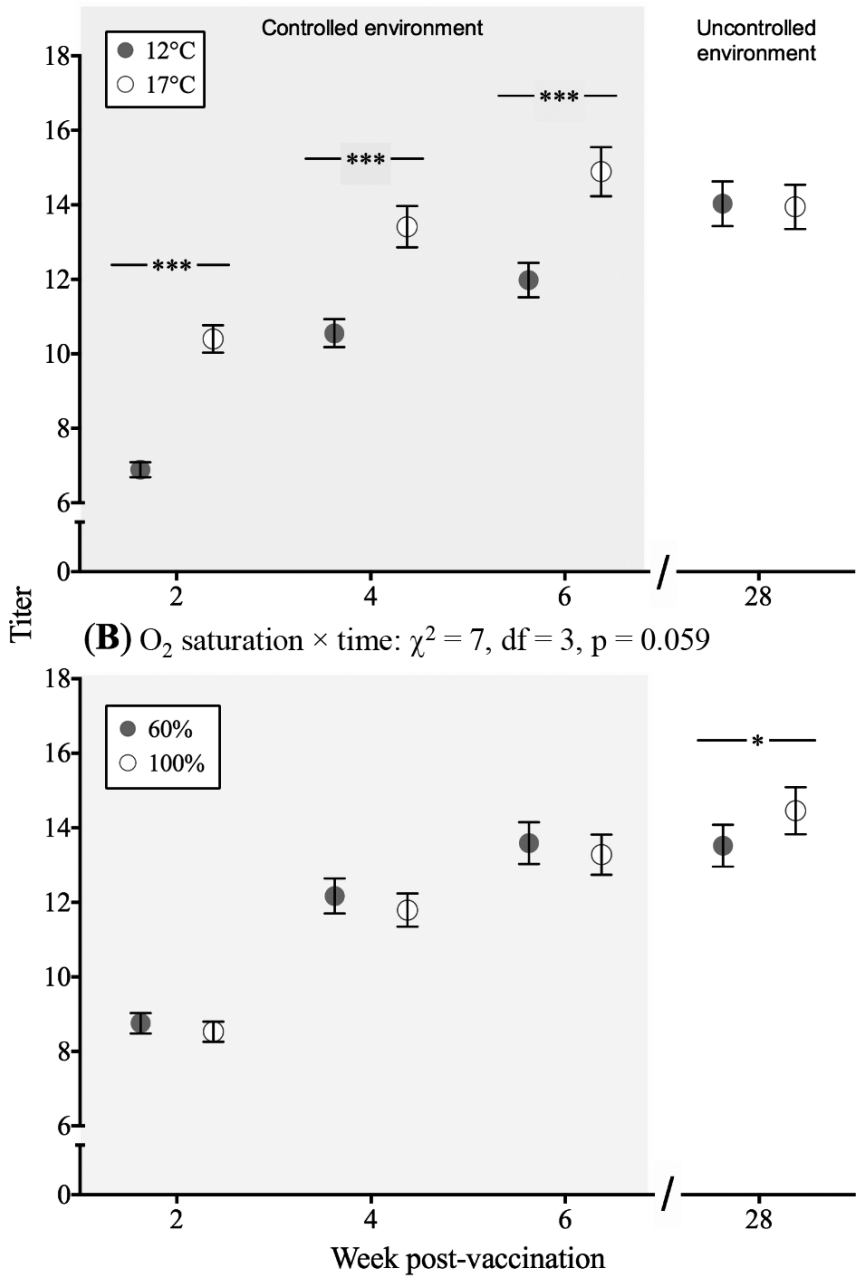

Fig. 4. Effect of (A) water temperature and (B) oxygen saturation at vaccination on antibody titres over time in vaccinated Atlantic salmon. The results from linear models are presented. Data are means $\pm 95 \%$ CI $\left(n=20\right.$ group $^{-1}$ time $\left.^{-1}\right)$. Asterisks indicate a significant effect of temperature $/ \mathrm{O}_{2}$ saturation within a given time point (post hoc, least square means, $* p<0.05, * * * p<0.001)$

showed some overlap with normal fish (6 of the 1354 'normal' fish had a CF $<0.94$, but these 6 fish all weighed $>290 \mathrm{~g}$ ). In all instances, the models for body mass and body condition that included an interaction between losers and time had a lower BIC score than the model without the interaction (body mass, -158 vs. 35 ; body condition, -955 vs. -933 for models with and without the interaction, respectively), providing evidence that loser effects are transient over time. Subsequent analysis showed that losers were equal in body mass and condition compared to 'normal' fish in October 2016, equal in body mass but with a lower condition in November 2016, but had significantly lower mean body mass and condition in April 2017 (Fig. 5).
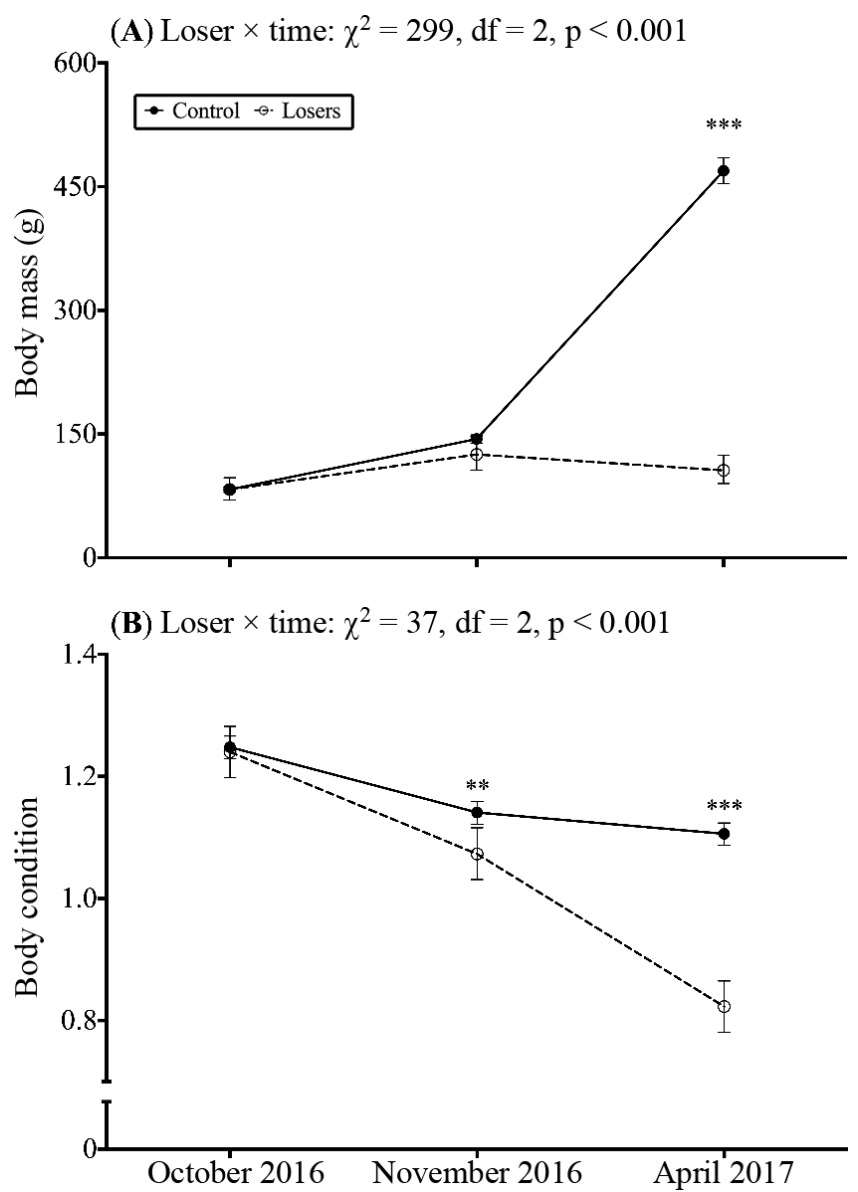

Fig. 5. Body mass and condition of Atlantic salmon reared at $17^{\circ} \mathrm{C}$ and $60 \% \mathrm{O}_{2}$ saturation for $7 \mathrm{wk}$ followed by a further 28 wk in a sea-cage. (A) Body mass and (B) body condition for 'losers' and control individuals over time. Data include means $\pm 95 \%$ CI $\left(n=13-140\right.$ group $^{-1}$ time $\left.^{-1}\right)$. Asterisks indicate a significant loser effect within a given time point (post hoc, least square means, $* * \mathrm{p}<0.01), * * * \mathrm{p}<0.001$

\section{DISCUSSION}

We investigated whether growth following vaccination was associated with environmental conditions expected to alter or limit metabolic rate and found no support for our hypothesis that vaccination leads to an increase in metabolic demand, resulting in reduced growth. However, we observed long-term effects on growth relating to short-term hypoxia treatment following co-treatment at $17^{\circ} \mathrm{C}$, but not $12^{\circ} \mathrm{C}$.

Environmental conditions were manipulated for $7 \mathrm{wk}$ post vaccination to see whether they influenced vaccine-reduced growth. Based on cyclic hypoxia studies, we expected $60 \% \mathrm{O}_{2}$ saturation at $17^{\circ} \mathrm{C}$ to be the most challenging condition (Remen et al. 2012, 2013). Indeed, the fish reared at $17^{\circ} \mathrm{C}$ and $60 \% \mathrm{O}_{2}$ saturation showed a significant reduction in growth and body size at the end of the controlled environmental period 
compared to those at $100 \% \mathrm{O}_{2}$ saturation, but the same hypoxia effect was not seen in $12^{\circ} \mathrm{C}$ fish. A level of around $39 \% \mathrm{O}_{2}$ saturation is expected to be physiologically challenging to salmon at $12^{\circ} \mathrm{C}$ (Remen et al. 2013). However, neither water temperature nor $\mathrm{O}_{2}$ saturation interacted with vaccination, suggesting that direct costs to metabolism do not explain the reductions in growth observed following vaccination. Although theorised to be energetically costly, the direct metabolic cost of mounting an immune response is generally difficult to demonstrate, and studies in rainbow trout have shown inconsistent results. For example, vaccines without adjuvant have not led to significant increases in metabolic rate (Ackerman et al. 2000, Skinner et al. 2010, Zanuzzo et al. 2015). However, antigens combined with adjuvants have led to instances of increased metabolic rate (Skinner et al. 2010), although the effect is probably dependent on the type of adjuvant and antigens included in the formulation (Ackerman et al. 2000). In those instances where the standard metabolic rate did increase after exposure to adjuvanted vaccines, there was no subsequent reduction in growth (Ackerman et al. 2000, Skinner et al. 2010). Although we did not measure standard metabolic rate in the current study, in a parallel study using the same vaccine and fish stock, there was no effect of vaccination on routine metabolic rate in an experiment lasting $30 \mathrm{~d}$ post vaccination, although vaccinated fish grew more slowly (Torgersen et al. 2017). Taken together, we found no evidence to support the hypothesis that our vaccine reduced growth due to an increase in metabolic demand in salmon.

A number of mechanisms could have disguised the metabolic cost of vaccination. Firstly, fish were fed throughout the study, and feeding has a metabolic burden. Therefore, feed intake could be adjusted in response to vaccination. Although we are unable to address this in the current study, as vaccinated and unvaccinated fish shared the same tanks, previous studies have shown that short-term reductions in feed intake following vaccination in salmon can lead to a $20 \%$ reduction in growth $32 \mathrm{~d}$ post vaccination (Sørum \& Damsgård 2004). The cause of reduced feeding may be related to vaccine-induced peritonitis reducing short-term feeding/appetite (Bjørge et al. 2011). Alternatively, vaccinated fish could have reduced the extent of the immune response under more demanding environmental conditions to conserve energy. Here, we found that antibody titres were responsive to water temperature and $\mathrm{O}_{2}$ saturation, but the effects were not those expected if metabolism was restricting the antibody response. For example, the $17^{\circ} \mathrm{C}$ fish showed a more rapid antibody response than those vaccinated at $12^{\circ} \mathrm{C}$, and the effect of $\mathrm{O}_{2}$ saturation was not apparent during the period of controlled environmental conditions when the fish were actually experiencing hypoxia, it only occurred later once the fish were transferred to common-garden rearing with uncontrolled environmental conditions.

We found effects of both water temperature and $\mathrm{O}_{2}$ saturation on the antibody response that is in line with previous studies. For example, salmon vaccinated against Vibrio salmonicida at $2{ }^{\circ} \mathrm{C}$ showed a delayed or suppressed antibody response compared to salmon vaccinated at $10^{\circ} \mathrm{C}$ (Eggset et al. 1997), similar to our current finding of a quicker antibody response at 17 vs. $12^{\circ} \mathrm{C}$. Regarding hypoxia, a study in Nile tilapia Oreochromis niloticus vaccinated against $V$. anguillarum found that $55 \% \mathrm{O}_{2}$ saturation reduced and delayed the antibody response compared to $85 \% \mathrm{O}_{2}$ saturation (Gallage et al. 2016), similar to the results in the current work. In addition, Atlantic salmon experiencing cyclic hypoxia, between 44 and $65 \% \mathrm{O}_{2}$ saturation, had a $38-56 \%$ reduction in head kidney leucocyte respiratory burst activity compared to those on normoxia (Burt et al. 2013). However, it should be noted that the lower antibody levels in the 60 vs. $100 \% \mathrm{O}_{2}$ saturation groups in this study were not apparent during the initial $6 \mathrm{wk}$ period of controlled environmental conditions, but came later when the fish were all common-garden reared with uncontrolled environmental conditions. Further work is required to determine whether this is a genuine suppression of the immune system or a delay in the antibody peak.

The growth difference between vaccinated and unvaccinated fish occurred within the initial $7 \mathrm{wk}$ period of controlled environmental conditions and remained evident at the end of the trial. However, the vaccinated fish displayed some 'catch-up' growth when reared for 5 mo under uncontrolled natural conditions. This may suggest that a short-term reduction in feed intake is the main cause of the growth disparity caused by vaccination (Sørum \& Damsgård 2004). In contrast, those fish that experienced $60 \% \mathrm{O}_{2}$ saturation and $17^{\circ} \mathrm{C}$ showed a chronic reduction in growth rates that persisted even after 5 mo in common garden conditions, suggesting that a different mechanism is operating on growth compared to the vaccine effect, especially as there was no additive effect between $\mathrm{O}_{2}$ saturation and vaccination. Of note, we cannot attribute the vaccine effect on growth to the occurrence of skeletal deformities. Previously, in some instances, vaccination has been found to lead to an increase in skeletal deformity prevalence (e.g. Berg et al. 2006) that is known to reduce growth 
(Hansen et al. 2010). However, we found no vaccine effect on deformities after $120 \mathrm{~d}$ in seawater, similar to other studies (e.g. Fraser et a. 2014).

$\mathrm{O}_{2}$ saturation during the period of controlled environmental conditions had long-term effects on growth in fish that initially experienced $17^{\circ} \mathrm{C}$. Five months post hypoxia exposure, the 60,70 , and $80 \% \mathrm{O}_{2}$ saturation groups were 26,10 , and $7 \%$ smaller, respectively, than those that experienced $100 \% \mathrm{O}_{2}$ saturation. The reduction in growth during hypoxia is expected to be related to lower feed intake as a mechanism to lower metabolic demands under challenging conditions (Remen et al. 2012). Previously, salmon exposed to $60 \% \mathrm{O}_{2}$ at $16^{\circ} \mathrm{C}$ showed a $6 \%$ reduction in feed intake and growth rates during the hypoxia exposures, but showed compensatory growth after the cessation of cyclic hypoxia treatment (Remen et al. 2014). We report no evidence for compensatory growth $5 \mathrm{mo}$ post hypoxia treatment. Indeed, the drop-off in growth between the $17^{\circ} \mathrm{C}$ and $\leq 80$ and $100 \% \mathrm{O}_{2}$ saturation groups increased post hypoxia exposure. As there was no drop-off in growth in those fish that experienced low $\mathrm{O}_{2}$ saturation at $12^{\circ} \mathrm{C}$, hypoxia alone is unlikely to explain the current findings. Given that the metabolically challenging conditions of $17^{\circ} \mathrm{C}$ and $60-70 \% \mathrm{O}_{2}$ saturation were experienced during the parr-smolt transformation, a process that is essential for the long-term growth performance of the fish (Björnsson et al. 2011), it may be that this developmental process has been hindered in some aspect, although we found no treatment effect on gill markers of smoltification. Further work into the long-term effects of hypoxia and water temperature during the parr-smolt transformation would be of interest.

We observed a positive association between water temperature during the $7 \mathrm{wk}$ of controlled environmental conditions and sexual maturation and cataracts, but no effect on skeletal deformities. The temperature effect on sexual maturation has been observed previously (Fjelldal et al. 2011, Imsland et al. 2014). The current $7 \mathrm{wk}$ exposure to $17^{\circ} \mathrm{C}$ during smoltification resulted in fully mature males out-of-season in April 2017, as previously observed by Fjelldal et al. (2011). We also note a trend for reduced prevalence of sexual maturation in the $17^{\circ} \mathrm{C} / 60 \% \mathrm{O}_{2}$ saturation group (Fig. 3A), suggesting that this temperature effect may be related to growth acceleration, but this requires further experimentation. Similarly, cataracts were more prevalent in the fastest-growing groups around sea transfer, unvaccinated fish kept at $17^{\circ} \mathrm{C}$, which conforms with the current literature (Bjerkås et al. 2001) and would suggest growth rate during a critical developmental window is a risk factor for cataract development. Previously, salmon exposed to $16^{\circ} \mathrm{C}$ around smoltification have been found to have an increased prevalence of skeletal deformities (Grini et al. 2011, Fraser et al. 2019b). In the current work, we found that deformities were few and could not be linked to temperature or oxygen saturation around smoltification. The inconsistency may be explained by the length of the study. For example, in the study by Fraser et al. (2019b), temperature treatments around smoltification increased skeletal deformity prevalence at harvest size after $533 \mathrm{~d}$ in seawater, whereas no effects were observed at sea transfer or following $120 \mathrm{~d}$ in seawater.

Losers were mainly found among fish reared at $60 \% \mathrm{O}_{2}$ saturation at $17^{\circ} \mathrm{C}$. To date, there is very little information on losers (Stien et al. 2013), although they are a concern for the industry with respect to reduced animal welfare (Vindas et al. 2016) and economic loss. We found that biometric data could not be used to identify losers in October, but a minor reduction in growth could be detected as early as November before the more dramatic decrease in performance following sea transfer. Further research is required to understand the contributing factors to this condition. However, as losers were most apparent under the most challenging environment, the $7 \mathrm{wk}$ period of high water temperature and low $\mathrm{O}_{2}$ saturation, one may suspect that the losers in the current study may be individuals that could not tolerate physiologically demanding environmental conditions. As the growth of losers was already impaired in November 2016, this could indicate a disruption of physiology during the parr-smolt transformation that may then have led to the more substantial negative effects on growth upon entering the seawater environment. Alternatively, it would also be of interest to screen for infectious agents, as fish may be at an increased risk of infection when environmental conditions are unfavourable, such as during high water temperature and periods of hypoxia (Bowden 2008). However, further work in this area is required.

To conclude, there was no interaction between environmental conditions expected to alter metabolic rate and vaccine-induced growth reduction. Therefore, the reduced growth observed following vaccination is unlikely to be related to alterations in basal metabolism.

Acknowledgements. This study was funded by MSD Animal Health Norway. We thank the technical staff at IMR Matre for fish husbandry. The present experiment was approved by the Norwegian Animal Research Authority and performed according to relevant animal welfare regulations (FOTS 10182). 


\section{LITERATURE CITED}

Ackerman PA, Iwama GK, Thornton JC (2000) Physiological and immunological effects of adjuvanted Aeromonas salmonicida vaccines on juvenile rainbow trout. J Aquat Anim Health 12:157-164

Aho K, Derryberry D, Peterson T (2014) Model selection for ecologists: the worldviews of AIC and BIC. Ecology 95: 631-636

Bagenal TB, Tesch FW (1978) Age and growth. In: Bagenal TB (ed) Methods for assessment of fish production in fresh waters. Blackwell Scientific Publications, Oxford, p 101-136

Berg A, Rødseth OM, Tangerås A, Hansen T (2006) Time of vaccination influences development of adhesions, growth and spinal deformities in Atlantic salmon Salmo salar. Dis Aquat Org 69:239-248

Bjerkås E, Bjørnestad E, Breck O, Waagbø R (2001) Water temperature regimes affect cataract development in smolting Atlantic salmon, Salmo salar L. J Fish Dis 24:281-291

Bjørge MH, Nordgreen J, Janczak AM, Poppe T, Ranheim B, Horsberg TE (2011) Behavioural changes following intraperitoneal vaccination in Atlantic salmon (Salmo salar). Appl Anim Behav Sci 133:127-135

Björnsson BT, Stefansson SO, McCormick SD (2011) Environmental endocrinology of salmon smoltification. Gen Comp Endocrinol 170:290-298

Bowden TJ (2008) Modulation of the immune system of fish by their environment. Fish Shellfish Immunol 25:373-383

Brudeseth BE, Wiulsrød R, Fredriksen BN, Lindmo K and others (2013) Status and future perspectives of vaccines for industrialised fin-fish farming. Fish Shellfish Immunol 35:1759-1768

Burt K, Hamoutene D, Perez-Casanova J, Gamperl AK, Volkoff H (2013) The effect of intermittent hypoxia on growth, appetite and some aspects of the immune response of Atlantic salmon (Salmo salar). Aquacult Res 45:124-137

Cho CY (1992) Feeding systems for rainbow trout and other salmonids with reference to current estimates of energy and protein requirements. Aquaculture 100:107-123

Eggset G, Mikkelsen H, Angell Killie JE (1997) Immunocompetence and duration of immunity against Vibrio salmonicida and Aeromonas salmonicida after vaccination of Atlantic salmon (Salmo salar L.) at low and high temperatures. Fish Shellfish Immunol 7:247-260

Fjelldal PG, Hansen T, Huang T (2011) Continuous light and elevated temperature can trigger maturation both during and immediately after smoltification in male Atlantic salmon (Salmo salar). Aquaculture 321:93-100

Fjelldal PG, Schulz R, Nilsen TO, Anderson E, Norberg B, Hansen TJ (2018) Sexual maturation and smoltification in domesticated Atlantic salmon (Salmo salar L.) - Is there a developmental conflict? Physiol Rep 6:e13809

Fraser TWK, Hansen T, Mayer I, Skjæraasen JE, Glover KA, Sambraus F, Fjelldal PG (2014) The effect of triploidy on vaccine side-effects in Atlantic salmon. Aquaculture 433: 481-490

Fraser TWK, Mayer I, Hansen T, Poppe TT, Skjæraasen JE, Koppang EO, Fjelldal PG (2015) Vaccination and triploidy increase relative heart weight in farmed Atlantic salmon, Salmo salar L. J Fish Dis 38:151-160

Fraser TWK, Fjelldal PG, Schulz R, Norberg B, Hansen TJ (2019a) Termination of puberty in out-of-season male Atlantic salmon smolts. Comp Biochem Physiol A Mol Integr Physiol 232:60-66
Fraser TWK, Witten PE, Albrektsen S, Breck O and others (2019b) Phosphorus nutrition in farmed Atlantic salmon (Salmo salar): life stage and temperature effects on bone pathologies. Aquaculture 511:734246

Gallage S, Katagiri T, Endo M, Futami K, Endo M, Maita M (2016) Influence of moderate hypoxia on vaccine efficacy against Vibrio anguillarum in Oreochromis niloticus (Nile tilapia). Fish Shellfish Immunol 51:271-281

* Grini A, Hansen T, Berg A, Wargelius A, Fjelldal PG (2011) The effect of water temperature on vertebral deformities and vaccine-induced abdominal lesions in Atlantic salmon, Salmo salar L. J Fish Dis 34:531-546

*Handeland SO, Wilkinson E, Sveinsbø B, McCormick SD, Stefansson SO (2004) Temperature influence on the development and loss of seawater tolerance in two fastgrowing strains of Atlantic salmon. Aquaculture 233: 513-529

KHansen T, Fjelldal PG, Yurtseva A, Berg A (2010) A possible relation between growth and number of deformed vertebrae in Atlantic salmon (Salmo salar L.). J Appl Ichthyol 26:355-359

* Haugarvoll E, Bjerkås I, Szabo NJ, Satoh M, Koppang EO (2010) Manifestations of systemic autoimmunity in vaccinated salmon. Vaccine 28:4961-4969

Houde ED, Scheckter RC (1981) Growth rates, rations and cohort consumptions of marine fish larvae in relation to prey concentration. Rapp P-V Réun Cons Int Explor Mer 178:441-453

Houde ALS, Günther OP, Strohm J, Ming TJ and others (2019) Discovery and validation of candidate smoltification gene expression biomarkers across multiple species and ecotypes of Pacific salmonids. Conserv Physiol 7: coz051

Hvas M, Folkedal O, Imsland A, Oppedal F (2017) The effect of thermal acclimation on aerobic scope and critical swimming speed in Atlantic salmon Salmo salar. J Exp Biol 220:2757-2764

Imsland AK, Handeland SO, Stefansson SO (2014) Photoperiod and temperature effects on growth and maturation of pre- and post-smolt Atlantic salmon. Aquacult Int 22: $1331-1345$

Koppang EO, Bjerkås I, Haugarvoll E, Chan EKL and others (2008) Vaccination-induced systemic autoimmunity in farmed Atlantic salmon. J Immunol 181:4807-4814

* Kvamme BO, Gadan K, Finne-Fridell F, Niklasson L and others (2013) Modulation of innate immune responses in Atlantic salmon by chronic hypoxia-induced stress. Fish Shellfish Immunol 34:55-65

* Lenth RV (2016) Least-square means: the R package lsmeans. J Stat Softw 69:1-33

* Lochmiller RL, Deerenberg C (2000) Trade-offs in evolutionary immunology: Just what is the cost of immunity? Oikos 88:87-98

Love DC, Fry JP, Cabello F, Good CM, Lunestad BT (2020) Veterinary drug use in United States net pen salmon aquaculture: implications for drug use policy. Aquaculture 518:734820

* Midtlyng PJ, Lilllehaug A (1998) Growth of Atlantic salmon Salmo salar after intraperitoneal administration of vaccines containing adjuvants. Dis Aquat Org 32:91-97

*Midtlyng PJ, Reitan LJ, Lillehaug A, Ramstad A (1996) Protection, immune responses and side effects in Atlantic salmon (Salmo salar L) vaccinated against furunculosis by different procedures. Fish Shellfish Immunol 6: 599-613 
Mutoloki S, Alexandersen S, Evensen Ø (2004) Sequential study of antigen persistence and concomitant inflammatory reactions relative to side-effects and growth of Atlantic salmon (Salmo salar L.) following intraperitoneal injection with oil-adjuvanted vaccines. Fish Shellfish Immunol 16:633-644

Mutoloki S, Reite OB, Brudeseth B, Tverdal A, Evensen $\varnothing$ (2006) A comparative immunopathological study of injection site reactions in salmonids following intraperitoneal injection with oil-adjuvanted vaccines. Vaccine 24:578-588

Niklasson L, Sundh H, Fridell F, Taranger GL, Sundell K (2011) Disturbance of the intestinal mucosal immune system of farmed Atlantic salmon (Salmo salar), in response to long-term hypoxic conditions. Fish Shellfish Immunol 31:1072-1080

Remen M, Oppedal F, Torgersen T, Imsland AK, Olsen RE (2012) Effects of cyclic environmental hypoxia on physiology and feed intake of post-smolt Atlantic salmon: initial responses and acclimation. Aquaculture 326-329: 148-155

Remen M, Oppedal F, Imsland AK, Olsen RE, Torgersen T (2013) Hypoxia tolerance thresholds for post-smolt Atlantic salmon: dependency of temperature and hypoxia acclimation. Aquaculture 416-417:41-47

Remen M, Aas TS, Vågseth T, Torgersen T, Olsen RE, Imsland A, Oppedal F (2014) Production performance of Atlantic salmon (Salmo salar L.) postsmolts in cyclic hypoxia, and following compensatory growth. Aquacult Res 45: 1355-1366

Skinner LA, Schulte PM, Balfry SK, McKinley RS, LaPatra SE (2010) The association between metabolic rate,

Editorial responsibility: Tim Dempster,

Melbourne, Victoria, Australia immune parameters, and growth performance of rainbow trout, Oncorhynchus mykiss (Walbaum), following the injection of a DNA vaccine alone and concurrently with a polyvalent, oil-adjuvanted vaccine. Fish Shellfish Immunol 28:387-393

* Sørum U, Damsgård B (2004) Effects of anaesthetisation and vaccination on feed intake and growth in Atlantic salmon (Salmo salar L.). Aquaculture 232:333-341

* Stien LH, Bracke MBM, Folkedal O, Nilsson J and others (2013) Salmon Welfare Index Model (SWIM 1.0): a semantic model for overall welfare assessment of caged Atlantic salmon: review of the selected welfare indicators and model presentation. Rev Aquacult 5:33-57

* Torgersen T, Fjelldal PG, Hansen T (2017) Vaccination induced reduction in growth rate in salmon is not mediated through increased metabolic costs or reduced metabolic scope. Aquaculture Europe, Dubrovnik. https://www. was.org/easonline/AbstractDetail.aspx? $\mathrm{i}=8528$

Vindas MA, Johansen IB, Folkedal O, Höglund E and others (2016) Brain serotonergic activation in growth-stunted farmed salmon: adaption versus pathology. R Soc Open Sci 3:160030

Witten PE, Gil-Martens L, Huysseune A, Takle H, Hjelde K (2009) Towards a classification and an understanding of developmental relationships of vertebral body malformations in Atlantic salmon (Salmo salar L.). Aquaculture 295:6-14

Zanuzzo FS, Urbinati EC, Nash GW, Gamperl AK (2015) Steelhead trout Oncorhynchus mykiss metabolic rate is affected by dietary Aloe vera inclusion but not by mounting an immune response against formalin-killed Aeromonas salmonicida. J Fish Biol 87:43-53

Submitted: March 9, 2020; Accepted: June 3, 2020

Proofs received from author(s): July 18, 2020 